\title{
DETERMINATION OF LOCAL NITROGEN LOSS FOR EXPLOITATION OF SUSTAINABLE PRECISION AGRICULTURE: APPROACH DESCRIPTION
}

\author{
Francesco Marinello ${ }^{1,2}$, Simone Gatto ${ }^{3}$, Alessandro Bono ${ }^{1}$, Andrea Pezzuolo ${ }^{1}$ \\ ${ }^{1}$ University of Padova, Italy; ${ }^{2}$ NEOS srl, Spin off of the University of Padova, Italy; \\ ${ }^{3}$ Porto Felloni Agr., Italy \\ francesco.marinello@unipd.it
}

\begin{abstract}
Nitrogen management is an issue in agricultural sustainability. Compared to conventional tillage, precision agriculture practices can potentially improve nitrogen cycle efficiency, with positive benefits on crops, soils and environment. The present paper discusses the result of precision agriculture on nitrogen management, taking into account a 52 ha experimental site, in a private farm in a typical Po Valley field in north-eastern Italy, monitored from 2013 to 2015. The area is cultivated with corn (Zea mays) managed with variable rate application of fertilizer. Available data were combined in order to estimate with a $10 \times 10 \mathrm{~m}$ resolution the actual efficiency in Nitrogen utilization and to quantify local losses, mainly due to denitrification, volatilization or leaching. Results show how an average loss of $76 \mathrm{~kg} \cdot \mathrm{ha}^{-1}$ per year was found in the experimental site, and only $11.5 \%$ of the total area undergoing losses higher than $200 \mathrm{~kg} \cdot \mathrm{ha}^{-1}$. Clearly the identification of critical areas can help definition of correction actions to be implemented to reduce and minimize the impact on agriculture on environment.
\end{abstract}

Keywords: Nitrogen, precision agriculture, variable rate application, Automatic Resistivity Profiling.

\section{Introduction}

In the last years groundwater pollution has received an increasing amount of attention, especially in connection with intensive agriculture practices encompassing excessive application of nitrogen fertilizers [1;2]. Indeed, if by one hand nitrogen is one of the most important plant nutrients, generally improving final crop yield and quality parameters, on the other hand it also plays an important role in agroecosystem pollution. The pressure of over-fertilization on the environment is getting more awareness as deterioration of fresh water and climate change are becoming more critical [2]. As a consequence, the European Union has encouraged several research actions and enacted a directive (the so called Nitrates Directive) aimed to promote good agricultural practices and to eventually reduce the risks of pollution of groundwater (91/676/EEC).

Despite constant improvements in research and development of new techniques helping characterization of soil and plant status through implementation of proximal and remote sensors [3-6], determination of optimal nitrogen needs is still an issue, mainly due to the field temporal and spatial variability. Additionally, the response of the plants to $\mathrm{N}$ fertilization is very much influenced by soil as well as by weather conditions during the growing season.

An interesting approach includes implementation of a simulation model which has the capability of integrating information on crop, soil, meteorological conditions and management practices, and allows quantification of nutrient needs and utilization of the same nutrients when fertilizations are carried out $[7 ; 8]$. However, such model is very much influenced by the specific microbiological activity of the soil, by the status of the vegetation and by its interaction with soil nutrients, therefore reliable quantification of nitrogen loss and of its time and space variability need distributed and dense collection of data.

The present paper implements a model for quantification of nitrogen loss, taking advantage of soil and meteorological data and field-information from a precision farming approach [9]. As a consequence, data are available with a relatively high field resolution, eventually allowing determination of $\mathrm{N}$ loss with a $10 \mathrm{~m}$ lateral spacing. Such high resolution computation is interesting for exploitation of a so called "sustainable precision agriculture", where specific action can be defined on the basis of the minimization of local environmental impact rather than on simple maximization of profits.

\section{Materials and methods}

\section{Experimental site}

The experimental study here described was carried out in a typical Po Valley farm in the northeastern part of Italy (12.56738 N, 41.87194 East), specifically considering the growing seasons 2014 
and 2015. The farm is specialized in the cereal sector with over 350 hectares dedicated to corn and wheat. The experimental site covered an area of 52 hectares, managed for the two years under corn cultivation.

Comprehensive data sets were and are available for the whole farm, including:

- combine-monitored yield maps;

- Electrical Resistivity analysis for characterization of soil features, carried out through an Automatic Resistivity Profiling system (ARP);

- soil samples analyses on position selected on the basis of ARP maps, done before the beginning of the growing season 2014 and at the end of the growing season;

- meteorological data monitored taking advantage of a weather station (Pessl Instruments $\mathrm{GmbH}$, Weiz, Austria) installed in the central field of the experimental area.

For the whole period, the experimental fields were managed adopting the same machinery and practices. Specifically, for fertilization operations, variable rate distribution of urea $(46 \% \mathrm{~N})$ was carried out taking advantage of a self-calibrating spreader (Amazone ZA-V) with ISOBUS technology.

\section{Implemented model}

As discussed in many papers [2], the characterization of the nitrogen cycle is very difficult and requires knowledge or estimation of many internal and external factors in the process. For such reason, a simplified model has been implemented for the present research, including input and output nitrogen flows, based on available soil, plant and environmental data. For the developed experiment, such simplified model can be summarized as follows:

$$
\mathrm{N}_{2015}-\mathrm{N}_{2013}=\mathrm{N}_{\text {min }}+\mathrm{N}_{\text {fert }}+\mathrm{N}_{\text {fix }}-\mathrm{N}_{\text {crop }}-\mathrm{N}_{\mathrm{m}}
$$

where:

- $\mathrm{N}_{2013}$ and $\mathrm{N}_{2015}$ indicate the amount of nitrogen in the soil respectively available for the corn in the growing season 2014 and left in the soil at the end of the growing season 2015, after harvesting;

- $\mathrm{N}_{\min }$ is amount of mineralized nitrogen from organic matter in the two years;

- $\quad \mathrm{N}_{\text {fert }}$ is the total $\mathrm{N}$ dose distributed with mineral fertilization in seasons 2014 and 2015;

- $\mathrm{N}_{\text {fix }}$ is ascribable to atmospheric deposition and quantifies nitrogen fixed by rain and by the microbial fauna in 2014 and 2015;

- $\mathrm{N}_{\text {crop }}$ quantifies $\mathrm{N}$ removed from the harvested product, which is a function of the yields 2014 and 2015.

- $\mathrm{N}_{\mathrm{m}}$ indicates the amount of lost nitrogen or, in other words, the amount of nitrogen missing mainly ascribable to: denitrification and volatilisation (with loss of nitrogen into the atmosphere), and leaching (soil nitrates drained by water).

Additive and subtractive operations reflect respectively input and output flows. In an ideal condition, $\mathrm{N}_{\mathrm{m}}$ should in theory converge to zero. However this is not the case in actuall fertilization operations and in practical experiments: deviations are found, in such a way that the model can be rewritten as follows:

$$
\mathrm{N}_{\mathrm{m}}=\mathrm{N}_{2013}-\mathrm{N}_{2015}+\mathrm{N}_{\text {min }}+\mathrm{N}_{\text {fert }}+\mathrm{N}_{\text {fix }}-\mathrm{N}_{\text {crop }}
$$

In the following paragraph, the model equation (2) is considered, and relative terms are singularly computed to eventually estimate the missing nitrogen $\mathrm{N}_{\mathrm{m}}$.

\section{Data analysis}

For the present work different data sets have been used and processed taking advantage of commercial software: Farmworks (Trimble Navigation Limited, Sunnyvale, Cal.) for georeferencing and management, and SPIP (by Image Metrology, Hørsholm, Denmark) for computation and 3D rendering. Soil was firstly characterized through electrical resistivity measurements, based on an on the go automatic resistivity profiling system and providing information at different depths. ARP maps lateral resolution were usefully implemented to classify soil textures and to accordingly estimate apparent densities. 
In order to quantify nitrogen available in the soil (variables $\mathrm{N}_{2013}$ and $\mathrm{N}_{2015}$ ), selective sampling was carried out on 30 different positions, in October 2013 and October 2015. Each sample comprised $1.5 \mathrm{~kg}$ of soil collected from 6-7 sub-samples on a radius of $2.5 \mathrm{~m}$ from the reference position, at a standard $0.3 \mathrm{~m}$ depth. Total nitrogen (as a result of $\mathrm{N}$ available at the beginning of the cycle plus $\mathrm{N}$ mineralized from organic matter) was determined based on Near Infrared Spectroscopy (NIR) [10]. Data underwent a standard resampling weighted on a nearest-neighbor weighted function, in order to allow realization of a homogeneous map over the experimental field (Figures 1-1 and 1-2). Nitrogen percentages were eventually combined with soil densities in order to get $\mathrm{N}$ concentrations, as shown in three-dimensional renderings in Figures 1-3 and 1-4, where $\mathrm{x}$ and $\mathrm{y}$ axes represent positions in latitude and longitude and $\mathrm{z}$ axes represent average $\mathrm{N}$ content.
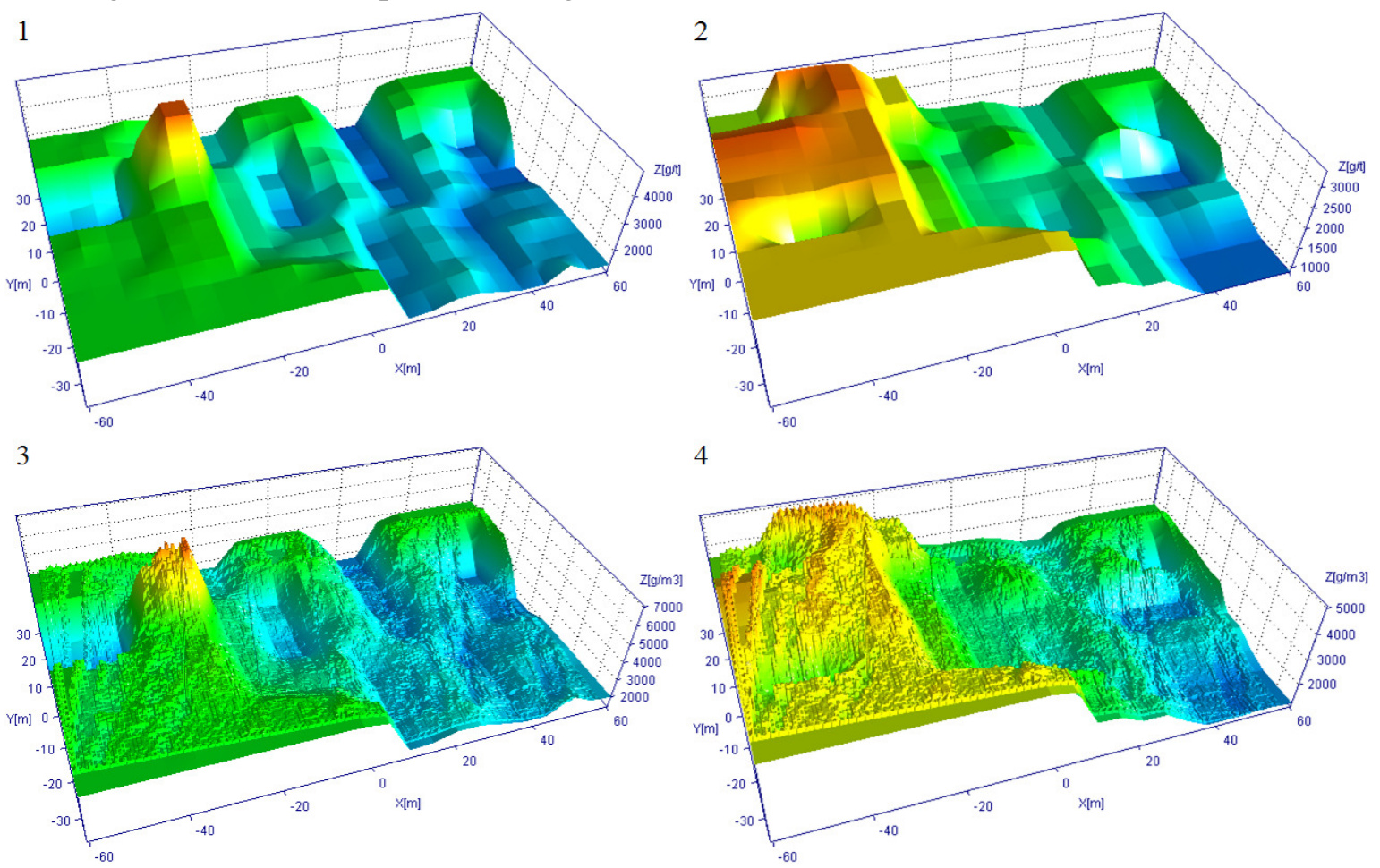

Fig. 1. Nitrogen available in the soil (resampled results): 1 - sampling 2013; 2 - sampling 2015; 3 - 2013 data corrected with soil densities; $4-2015$ data corrected with soil densities. In all of the cases the reported data overcome the perimeter of the experimental area.

The second contribution is the amount of mineralized nitrogen $\mathrm{N}_{\min }$ in this two-year period, resulting from the mineralization of organic matter (Figure 2-1). Its contribution was determined on the basis of a coefficient of mineralization variable between 0.6 and 1.8 and depending on the texture and on the $\mathrm{C} / \mathrm{N}$ ratio $[11 ; 12]$. Values have been eventually reduced, in order to take into account the occupation time of corn on soil (Figure 2-2).
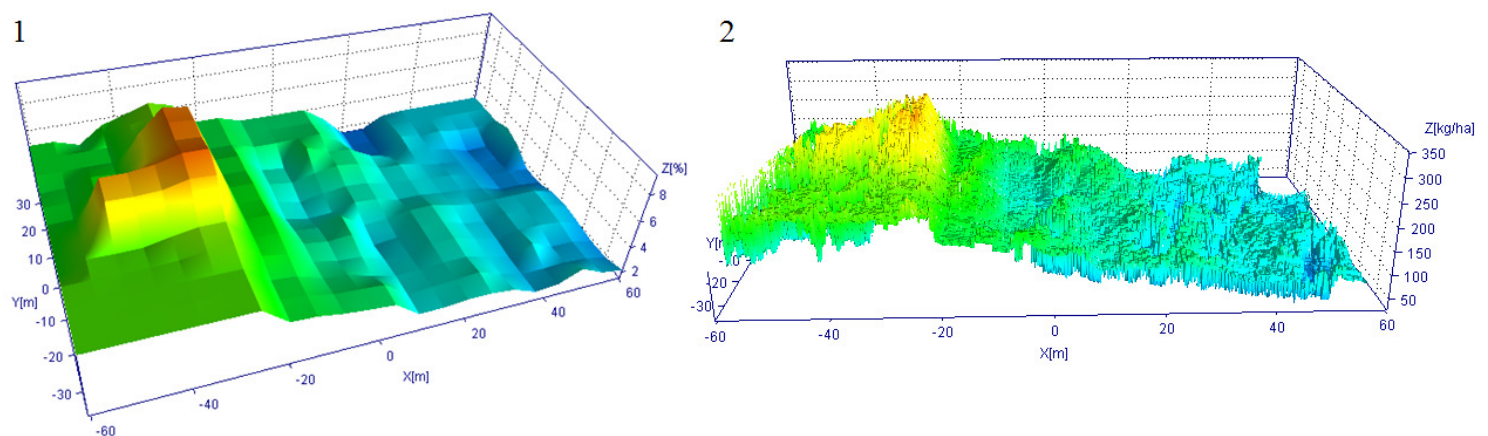

Fig. 2. Estimation of mineralized nitrogen: 1 - organic carbon available in the soil between 2013 and 2015; 2 - mineralized nitrogen, after time correction.

The third contribution is that arising from nitrogen fertilization. Prescription maps from variable rate $\mathrm{N}$ management, provided site specific $\mathrm{N}$ units for the whole experimental area. Data corrected for 
used fertilizer (urea) $\mathrm{N}$ content (46\%), produced the $\mathrm{N}_{\text {fert }}$ maps for growing seasons 2014 and 2015. As can be noticed in reported maps (see Figure 3-1), used prescription maps are theoretical distributions which most probably deviate to some extent from actual quantities of fertilizer spread on soil surface. Quantifying such values is practically very difficult, however, implementation of a self calibrating spreader machine allowed completion of precision distribution, minimizing such deviations.

The fourth contribution $\mathrm{N}_{\text {fix }}$ includes nitrogen derived from natural flows of this element in the soil or by nitrogen fixation, which can be ascribable to biological fixation or atmospheric fixation. With regard to the first one, it is due to the reduction to ammonia of elemental nitrogen performed by microorganisms in the soil or in symbiosis with plants. Such fixation has a limited relevance, having values in the range $0.5-1 \mathrm{~kg} \cdot \mathrm{ha}^{-1}$ for the considered experiment [13]. Conversely, a more important role is played by atmospheric fixation. Chemical analyses of rain water carried out by the Regional Agency for Environmental Protection in the district where the experimental site is located provided an average concentration of $\mathrm{N}$ of $2 \mathrm{mg} \cdot \mathrm{l}^{-1}$. Installed weather station measured $798.4 \mathrm{~mm}$ and $704.5 \mathrm{~mm}$ rainwater respectively in 2014 and 2015, with a total estimated fixed nitrogen as high as $30.1 \mathrm{~kg} \cdot \mathrm{ha}^{-1}$.

The last term $\mathrm{N}_{\text {crop }}$ of the model (2) is the net nitrogen uptake. It is a subtractive term of the model, since it causes an output $\mathrm{N}$ flow. Indeed, during the growing season, $\mathrm{N}$ is removed from the soil and accumulated by vegetative organs of the whole plant. It is worth noting that in the present work only $\mathrm{N}$ in grain was considered, since the rest of the vegetative part was left on the soil. Analyses carried out on corn grains provided an average nitrogen level equal to $1.52 \%$ percentage dry matter. Such value was combined with corn grain yield maps and moisture information in order to quantify corn grain N uptake. Resulting map is reported in Figure 3-2. Considering an average yield of 13.4 and $12.3 \mathrm{t} \cdot \mathrm{ha}^{-1}$ respectively in 2014 and 2015 , a total of $391 \mathrm{~kg} \cdot \mathrm{ha}^{-1}$ has been removed by corn grain in the two years.
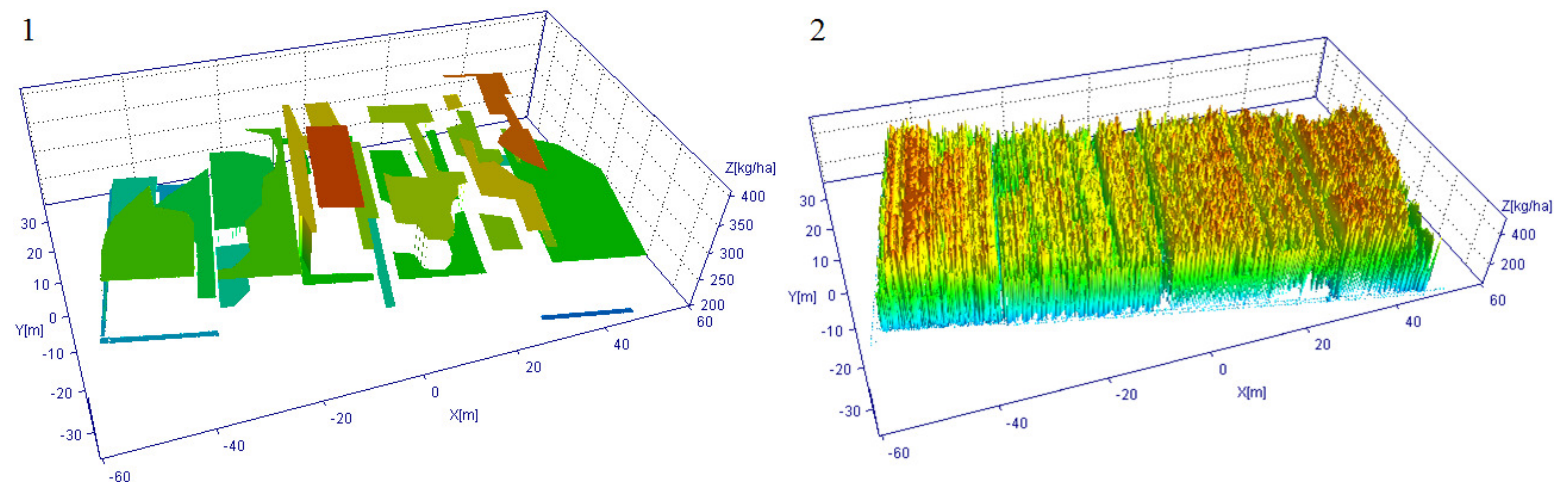

Fig. 3. Nitrogen fertilization and uptake: 1 - Fertilization prescription maps (doses 2014 and 2015); 2 - total corn grain $\mathrm{N}$ uptake in 2014 and 2015

\section{Results and discussion}

Combined maps eventually allowed to estimate the total missing nitrogen, due to denitrification, volatilization or leaching, in agreement with the proposed model (2) (Figure 4-1). Data were used also to estimate nitrogen distribution efficiency, computed as the local yield divided by local amount of nitrogen fertilization (Figure 4.2).
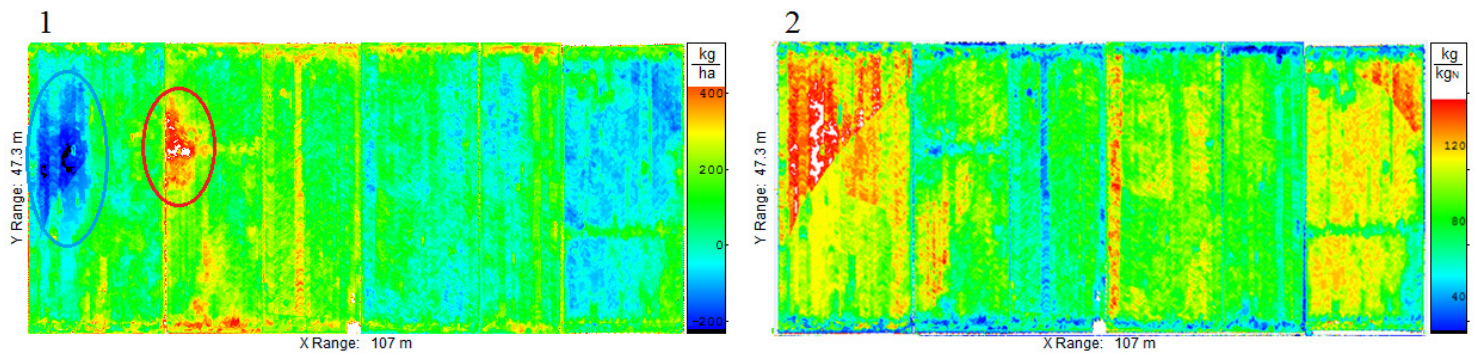

Fig. 4. Nitrogen performance after 2014 and 2015 growing seasons: 1 - nitrogen distribution efficiency and $2-$ missing nitrogen 
From missing nitrogen data, a total of $152 \mathrm{~kg} \cdot \mathrm{ha}^{-1}\left(76 \mathrm{~kg} \cdot \mathrm{ha}^{-1}\right.$ per year) was estimated on average on the 52 ha area, however it can be noticed how different results are achieved in different positions of the experimental field. Differences are to be ascribed mainly to yield variations and to fertilization practices. Higher losses levels recognizable in the borders are most probably a consequence of low grain yields, while the peak $\mathrm{N}$ loss identified by the red oval is perhaps due to a higher leaching rate in an area characterized by a sandy soil texture. On the other hand negative losses were estimated in other parts of the experimental field, as highlighted by the blue oval. Such areas, mainly characterized by relatively high yields, are therefore those presenting an higher efficiency in terms of environmental impact. Estimations of missing nitrogen comprised between -50 and $100 \mathrm{~kg} \cdot \mathrm{ha}^{-1}$, represented in Figure 5 by the light blue-green color, cover about $50 \%$ of the experimental area: this is representative of an almost ideal condition, where nitrogen uptake from the plant is well compensated by fertilizer distribution.

The usefulness of the final map developed on the basis of model (2) is clear: compared to nitrogen distribution efficiency, missing nitrogen map allows to discriminate the effects of different soil textures contributions, providing a whole high resolution perspective on nitrogen performance. Therefore, if nitrogen distribution efficiency provides a sort of feedback on the return on $\mathrm{N}$ investment, missing nitrogen keeps an environment oriented perspective. As a consequence it can provide an evidence of the goodness of agricultural practices, in a double viewpoint, allowing considerations both on environmental sustainability and on agronomic decisions during seeding and fertilization operations [14]. With specific reference to the experimental area, there is a $15 \%$ of the total area which would merit higher fertilization rates, while on the other hand a $11.5 \%$ of the experimental field exhibits an excess of nitrogen loss $\left(>200 \mathrm{~kg} \cdot \mathrm{ha}^{-1}\right)$ which would call for a reduction of $\mathrm{N}$ inputs, as can be simply appreciated by Figure 5.
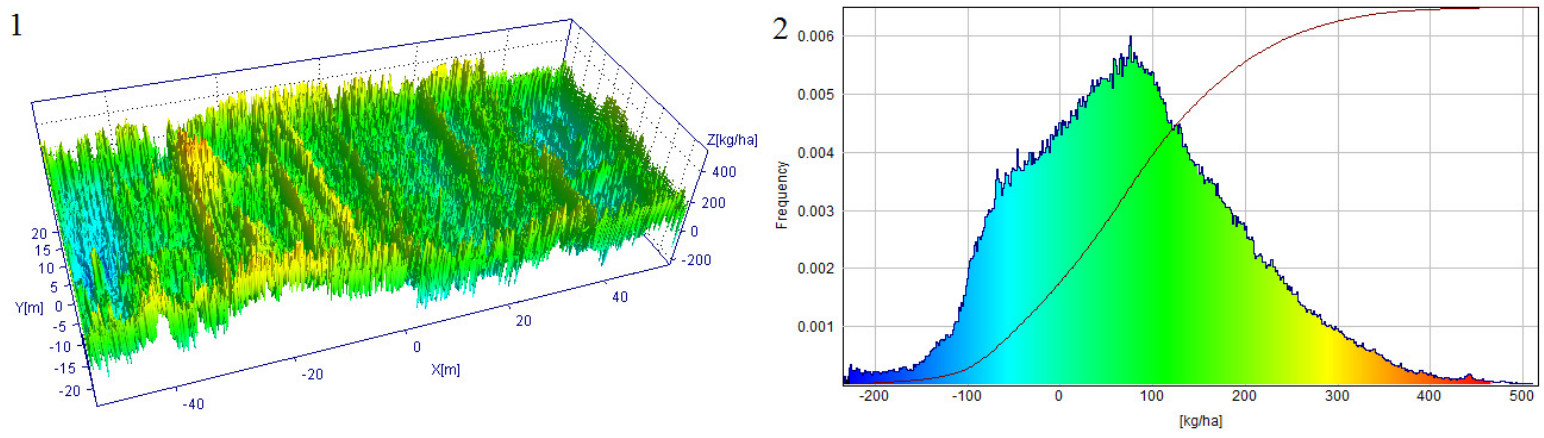

Fig. 5. Missing nitrogen after 2014 and 2015 growing seasons: 1 - three-dimensional representation and 2 - histogram distribution

\section{Conclusions}

1. The present work describes an approach for quantitative mapping of nitrogen loss with high field resolution

2. The model takes advantage of precision farming management tools, including soil and yield maps, and meteorological data

3. A case study was reported, on a 52 ha experimental area showing how most critical areas can be recognized as higher $\mathrm{N}$ loss field portions

4. The study shows how precision agriculture practices can be used to exploit nitrogen performance, giving indication for minimization of environmental impact.

\section{References}

1. Sudars R., Berzina L., Grinberga L., Analysis of agricultural run-off monitoring program results for estimation of nitrous oxide indirect emissions in Latvia. Engineering for Rural Development, vol. 15, 2016, pp. 1030-1035.

2. Basso B., Dumont B., Cammarano D., Pezzuolo A., Marinello F., Sartori L., Environmental and economic benefits of variable rate nitrogen fertilization in a nitrate vulnerable zone. Science of the Total Environment, vol. 545-546, 2016, pp. 227-235. 
3. Amaral L.R., Molin J.P., Portz G., Finazzi F.B., Cortinove L., Comparison of crop canopy reflectance sensors used to identify sugarcane biomass and nitrogen status. Precision Agriculture, vol. 16/1, 2015, pp. 15-28.

4. Marinello F., Pezzuolo A., Gasparini F., Arvidsson J., Sartori L., Application of the Kinect sensor for dynamic soil surface characterization. Precision Agriculture, vol. 5, 2015, pp. 1-12.

5. Cao Q., Miao Y., Li F., Gao X., Liu B., Lu D., Chen X., Developing a new Crop Circle active canopy sensor-based precision nitrogen management strategy for winter wheat in North China Plain. Precision Agriculture, vol. 18/1, 2017, pp. 2-18.

6. Dubbini M., Pezzuolo A., De Giglio M., Gattelli M., Curzio L., Covi D., Yezekyan T., Marinello F., Last generation instrument for agriculture multispectral data collection. CIGR Journal, 2017.

7. An X., Li M., Zheng L., Liu Y., Sun H., A portable soil nitrogen detector based on NIRS. Precision Agriculture, vol. 15/1, 2014, pp. 3-16.

8. Pezzuolo A., Basso B., Marinello F., Sartori L., Using SALUS model for medium and long term simulations of energy efficiency in different tillage systems. Applied Mathematical Sciences, vol. 8/129-132, 2014, pp. 6433-6445.

9. Pezzuolo A., Dumont B., Sartori L., Marinello F., De Antoni Migliorati M., Basso B., Evaluating the impact of soil conservation measures on soil organic carbon at the farm scale. Computers and Electronics in Agriculture, vol. 135, 2017, pp. 175-182.

10. Barthès B.G., Brunet D., Ferrer H., Chotte J.L., Feller C., Determination of total carbon and nitrogen content in a range of tropical soils using near infrared spectroscopy: Influence of replication and sample grinding and drying. Journal of Near Infrared Spectroscopy, vol. 14/5, 2006, pp. 341-348.

11. Shiratani E., Tohara Y., Shikasho S., Inoue H., Modeling of Nitrogen Discharge from a Barley Field. Rural and Environmental Engineering, vol. 33, 1997, pp. 37-53.

12. Morari F., Meggio F., Lunardon A., Scudiero E., Forestan C., Farinati S., Varotto S., Time course of biochemical, physiological, and molecular responses to field-mimicked conditions of drought, salinity, and recovery in two maize lines. Frontiers in Plant Science, vol. 6, 2015, pp. 1-15.

13. Arduini I., Masoni A., Ercol L., Mariotti, M., Grain yield, and dry matter and nitrogen accumulation and remobilization in durum wheat as affected by variety and seeding rate. European Journal of Agronomy, vol. 25, 2006, pp. 309-318. 